\title{
Studying the Effect of Process Parameters on Part Depth in Single Point Incremental Forming of AA1050-H14 Aluminum Alloy Sheets
}

\author{
Adel AL-SHAYEA, Abdulmajeed DABWAN, Adham E RAGAB, Mustafa M. NASR, Husam KAID
}

\begin{abstract}
Single Point Incremental Forming (SPIF) is an innovative forming approach for sheet metal that promises an inexpensive and flexible way to produce sheet metal parts in small batches. SPIF allows the production of complex geometries using a computer numerical control machine. In this study, SPIF has been conducted to investigate the effects of sheet thickness, tool diameter, feed rate, and step size on part depth. Statistical tools were used to design the experiments. Analysis of variance, as well as regression and optimization techniques were used to analyze the resulting part depth. Two levels of each parameter were included in a full factorial design. The study found several relations amongst the process parameters and the part depth. In summary, it was proved that the sheet thickness and tool diameter have the greatest effect on the part depth, whereas the step size has a small, but significant one.
\end{abstract}

Keywords: aluminum alloy AA 1050-H14; Design of Experiment; incremental forming; SPIF

\section{INTRODUCTION}

Incremental sheet metal forming (ISF) is a low volume production process. Therefore, this process is suitable for small batches and prototype production of small or unique sheet metal parts, due to its minimum cost. In addition, it can be used in a wide range of applications, such as highly customized medical and biomedical products [2, 21], automotive $[3,4]$ and aerospace [15] prototype parts, and components used in the calibration of model to void nucleation in Aluminum sheet metal for the automotive industry [18], in which the flexibility and speed of producing parts without expensive dies can greatly increase productivity.

From previous studies, several different processes have been proposed in ISF. One of them is the Single point incremental forming (SPIF), which has recently been the focus of extensive research. SPIF is an innovative approach applied for sheet metal forming in which a dedicated die is not necessary $[19,20]$. In this case, the process is designed and considered for single piece manufacturing, which may include prototype parts, small batch production, and economical processes. A traditional $\mathrm{CNC}$ machine is required for the manufacture of complex sheet metal dies [14]. Using SPIF, stamping or deep drawn parts can be formed without dies in a conventional CNC machine. The main SPIF concept is that the sheet metal blank can be incrementally deformed into the required shape by pressing a hemispherical stylus along a specified tool path [15]. $\mathrm{CAD} / \mathrm{CAM}$ software is used to define the tool path for the machining application. Moreover, in this technology, increasing the formability is helpful to the industrial applications that require high levels of deformation.

The SPIF process, like any other process, has parameters that affect the final shape of the produced parts. The effects of these parameters have stimulated researchers to find ways for optimizing them in order to achieve a good finish of the required part shape. For example, Ambrogio et al. [1] focused on the effects of the process parameters (sheet thickness, punch diameter, wall inclination angle, tool depth step, and total depth) on the accuracy of the part shape through a reliable statistical analysis. The obtained models were able to perform some effective actions (an analytical model was proposed to estimate and avoid the "over-deformation", thus minimizing the geometrical error) to improve the accuracy in a simple case study. Moreover, Bambach et al. [6] have contributed in this field by demonstrating with a pyramidal part that multistage forming can yield increased geometric accuracy compared to single stage forming. In another study, Husain et al. [13] experimentally measured the influence of five parameters (tool radius, sheet thickness, wall angle, step size, and prestraining level of the sheet) on the profile accuracy of a produced AA1060 SPIF part. A response surface method and regression analysis were used for the experiment design. The computation results show that the sheet thickness, wall angle, step size, and the interaction between the sheet thickness and wall angle are extremely significant in terms of their effect on profile accuracy.

As the research in this field developed, more effects of the SPIF process parameters have been studied and revealed. Centeno et al. [7] formed a conical frustum with circular generatrices by SPIF of AISI 304 metal sheets. The initial diameter of the truncated cone was $70 \mathrm{~mm}$, the initial drawing angle was $20^{\circ}$, the step size was alternated between $0.2 \mathrm{~mm}$ and $0.5 \mathrm{~mm}$ at each pass, the tool diameters were 20,10 , and $6 \mathrm{~mm}$, and the rotation of the tool was free. The final depth, proportional to the final forming angle, was recorded at the instant of failure. Three replicates of each SPIF test were carried out. The resulting final depths, and consequently the final forming angles, were repeated for each case and it was noticed that, as expected, formability in SPIF increased as the tool diameter decreased.

In another research work, Silva et al. [23] concluded that increasing the drawing angle increases the depth. In their study, the maximum angle was measured by measuring the depth at which the formed part broke. The step size was $0.5 \mathrm{~mm}$ per revolution. The tool rotation was free and its feed rate was $1000 \mathrm{~mm} / \mathrm{min}$. The lubricant was a water soap emulsion that was applied between the PVC sheet and the forming tool and the temperature was insignificant. The results show that complex parts can be manufactured with very high depth in polyvinylchloride (PVC) sheets using SPIF at room temperature.

In a research work regarding the part depth, Bagudanch et al. [5] analyzed the formability in terms of the maximum depth related to the spindle speed, tool 
diameter, feed rate, downward step size, and sheet thickness of PVC. The downward steps were 0.2 and 0.5 $\mathrm{mm}$; the tool diameters were 10 and $6 \mathrm{~mm}$; the feed rates were 3000 and $1500 \mathrm{~mm} / \mathrm{min}$; the spindle speeds were free, $1000 \mathrm{rpm}$, and $2000 \mathrm{rpm}$; and finally the sheet thicknesses were $2 \mathrm{~mm}$ and $1 \mathrm{~mm}$. The results showed that the spindle speed had a significant effect on the maximum depth of polymeric materials. In addition, the maximum depth was achieved by increasing the sheet formability.

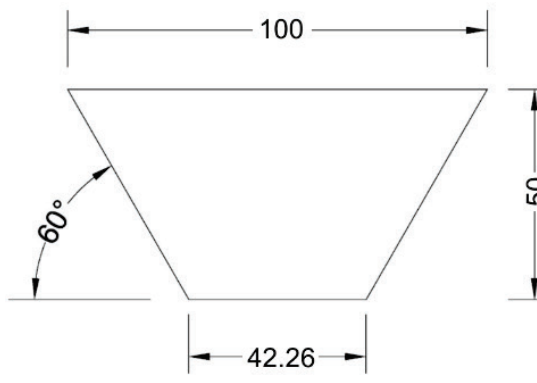

(a)

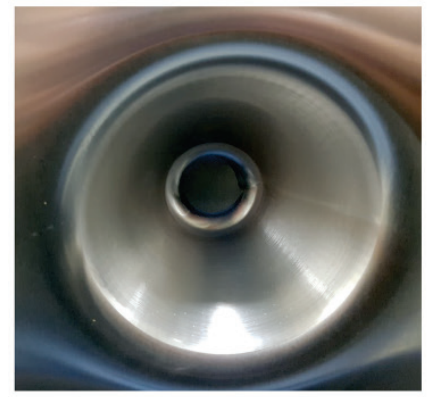

(d)

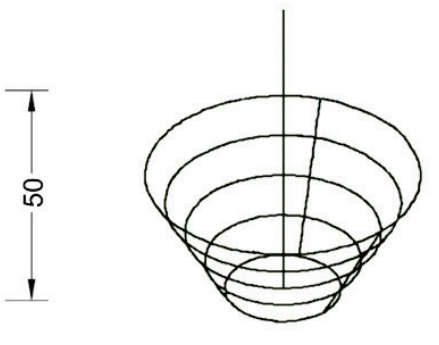

(b)

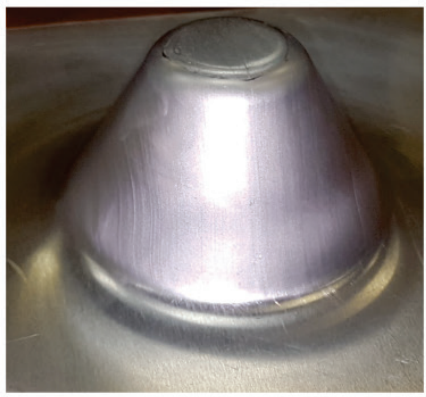

(e)

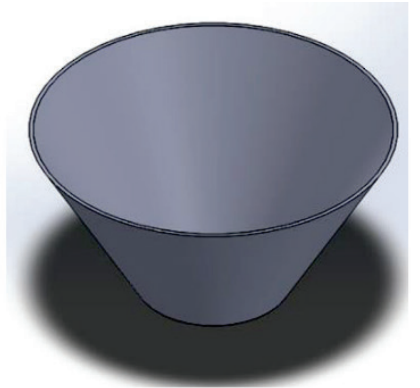

(c)

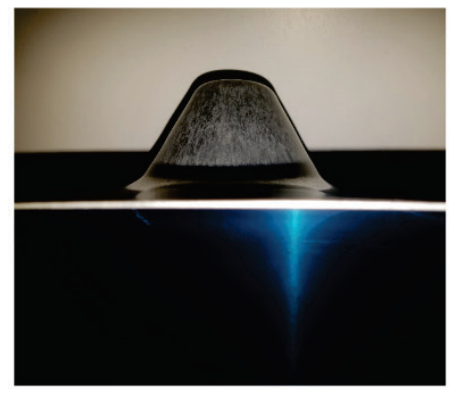

(f)

Figure 1 (a) The CAD Model (b) generated tool path (c) the solid CAD (d),(e) and (f) The actual produced part after shaping

In terms of the SPIF application on the different types of materials, Le et al. [17] presented some preliminary investigations on the applicability of SPIF to thermoplastic materials. The effects of the forming parameters on the material formability were investigated using an experimental design with three replications. Moreover, a cone-shaped part was considered with circular generatrices, depth, and varying wall angles. The formability of thermoplastic sheets based on SPIF is given by the maximum wall angle reached without failure and/or tearing. The results revealed that the tool size has a significant influence on the formability of thermoplastic sheets. In addition, interactions between tool size and feed rate, or step size and tool size have significant influences on the polymer formability, as well. Moreover, the expertise and knowledge of sheet metal on the SPIF process can be applied to thermoplastic sheets.

The impact of process factors that help researchers to develop a new integrated view on formability limits has been reported in the literature. This integrated view describes different explanations for the role of necking in fracture and is consistent with the experimental observations that have been reported in the past years. In this research area, the work of Silva et al. [24] studies the failure in SPIF and describes the effect of process factors, such as the tool radius, on the formability limits and the development of fracture. The study was carried out on aluminum AA1050-H111sheets with $1 \mathrm{~mm}$ thickness and the tool radius varied from 4 to $25 \mathrm{~mm}$ in order to inspect its effect on the failure mechanisms. Moreover, tensile and hydraulic bulge tests were used for independent determination of formability limits by necking and fracture, these tests were performed to benchmark the shapes for SPIF under laboratory conditions.

In most previous studies, the part accuracy and forming angle are limited, compared with the traditional stamping approach. The blank sheet boundary is fixed to prevent it from drawing during the forming process. The study of Do and Kim [9] introduces another view on the role of the blank shoulder area by considering hole lancing before the forming process. Artificial neural network (ANN) was used to clarify the springback dependence on the forming parameters and hole lancing.

The above studies show that the low accuracy obtained using SPIF still hinders its wide use in industrial applications. In addition, it shows that the quality of the formed part is affected significantly by the chosen processing parameters. This is obvious in the work of different researchers to evaluate part accuracy on various SPIF experiments that control different process parameters such as speed, tool diameter, incremental step size, feed rate, and sheet thickness. Different part sizes have been used as well to find their output performance on the formability in terms of surface roughness, part accuracy, forming angle, and forming force. However, there is a shortage in literature regarding the selection of parameters to determine the feasibility of the SPIF process in terms of the accuracy of the part depth. In addition, no attempt has been reported to optimize the SPIF parameters in this aspect. Therefore, the objective presented in this work is focused on studying the effect of the tool diameter, step size, sheet thickness, and feed rate on part depth. The design of experiment used was full factorial design to determine the significance of the selected parameters and the interactions amongst them. 


\section{EXPERIMENTATION \\ 2.1 CAD Model}

A CAD model is necessary to form the part by SPIF. The shape geometry was a truncated cone with a height of $50 \mathrm{~mm}$ and base diameter of $100 \mathrm{~mm}$, as shown in Fig. 1(a). Fig. 1(b) shows the development of the tool path generated by the CAD model. The solid nominal CAD is shown in Fig. 1(c). The produced parts are shown in Fig. 1(d), 1(e), and $1(\mathrm{f})$. The spiral tool path was generated using
MASTERCAM software to perform the forming of the sheet. The transition step method was used to create the tool contours [16]. The tool forms the part along one circle, and then it moves down the programmed step size to form the next circle. The process was repeated until the part was fully formed. For each part, the tool movement speed along the formed circles was constant and equal to the programmed feed rate as shown in Fig. 2.
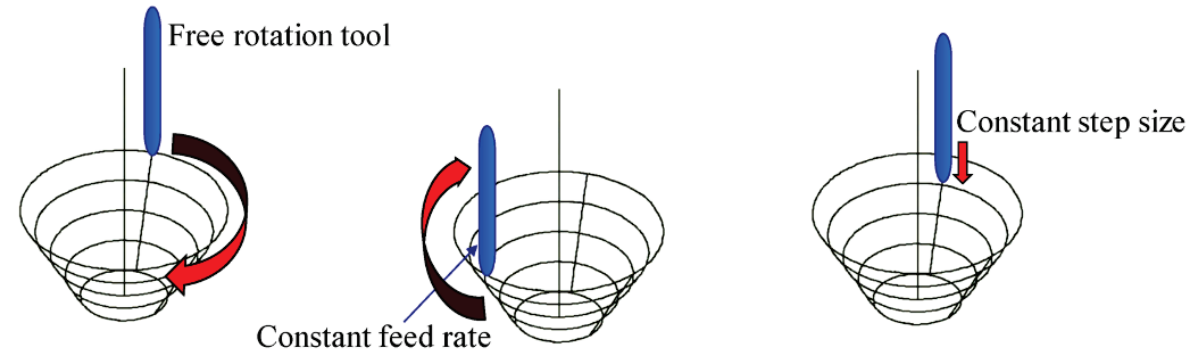

Figure 2 The trajectory (tool path) of the process

\subsection{Fixture Design}

A fixture is necessary to support the sheet on the working area. Fig. 3(a) shows the designed fixture, which was clamped to the working table of the CNC machine. The designed whole fixture consisted of three parts: the upper plate, which was used to hold the sheet over the middle plate as shown in Fig. 3(b), the middle plate, which was used to support the sheet, as shown in Fig. 3(c), and the lower plate, whose guide and push were fixed on the CNC machine as shown in Fig. 3(d). The working area was $200 \times 200 \mathrm{~mm}$ while the workpiece dimensions were 240 $\times 240 \mathrm{~mm}$.

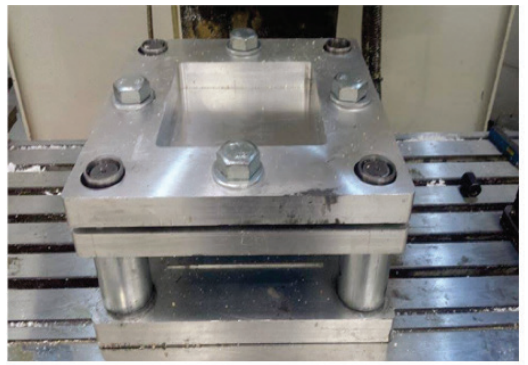

(a)

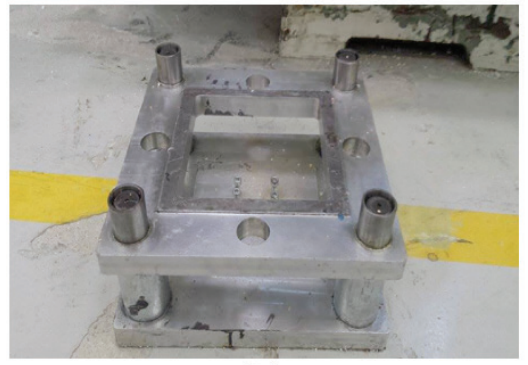

(c)

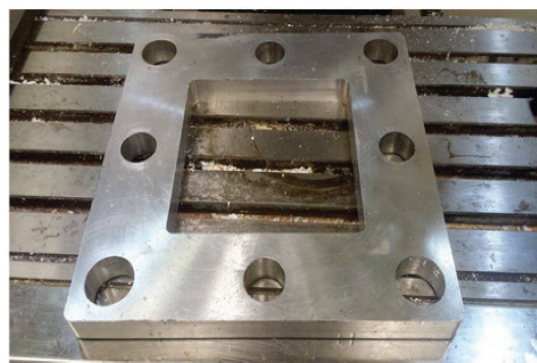

(b)

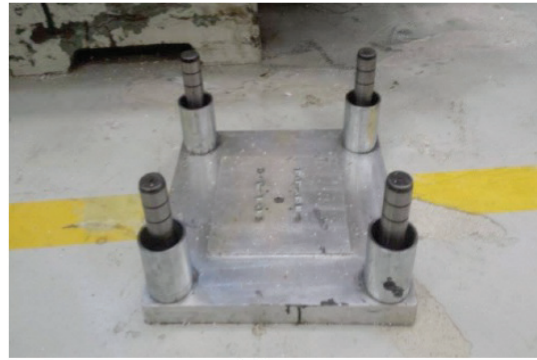

(d)

Figure 3 Workpiece fixture; (a) Workpiece fixture (b), (c) and (d) subassembly for workpiece fixture

\subsection{Material}

In this study, a commercial and commonly used aluminum alloy AA 1050-H14 was used. The composition of the material was tested by a SPECTRO machine for the two samples; Tab. 1 shows the composition of these samples. The mechanical properties were tested for the used material by a Zwick/Roell universal testing machine; Tab. 2 shows the test results.
Table 1 Chemical composition of the selected material

Table 1 Chemical composition of the selected material
\begin{tabular}{|c|c|c|c|c|c|}
\hline Sample & $\mathrm{Al}$ & $\mathrm{Fe}$ & $\mathrm{Si}$ & $\mathrm{Ti}$ & Other \\
\hline 1 & 0.9950 & 0.00360 & 0.000496 & 0.000205 & 0.00000699 \\
\hline 2 & 0.9950 & 0.00368 & 0.000480 & 0.000216 & 0.000624 \\
\hline
\end{tabular}

Table 2 Mechanical properties of the selected material

\begin{tabular}{|c|c|c|c|c|}
\hline $\begin{array}{c}\text { Material } \\
\text { code }\end{array}$ & $\begin{array}{c}\text { Yield } \\
\text { Strength } \\
\left(\sigma_{y}\right) \\
\mathrm{MPa}\end{array}$ & $\begin{array}{c}\text { Ultimate } \\
\text { Tensile } \\
\text { Strength }\left(\sigma_{U T S}\right) \\
\mathrm{MPa}\end{array}$ & $\begin{array}{c}\text { Elongation } \\
\text { at Break }(A) \\
\mathrm{mm}\end{array}$ & $\begin{array}{c}\text { Young } \\
\text { Modulus } \\
(E) \\
\mathrm{MPa}\end{array}$ \\
\hline $\begin{array}{c}\text { AA1050- } \\
\text { H14 }\end{array}$ & 128 & 117.5 & 8.45 & 67648 \\
\hline
\end{tabular}


Both material composition and mechanical properties were measured from the used sheets by the authors. Nine samples were laser cut from the sheet at angles $90^{\circ}, 45^{\circ}$ and $0^{\circ}$ degrees with respect to the sheet rolling direction. The mean anisotropy coefficient $\bar{R}$ was obtained as declared by Kalpakjian, Schmid et al. [16], as shown in the following equation.

$$
\bar{R}=\frac{R_{0}+2 R_{45}+R_{90}}{4}
$$

The normal anisotropy $R$ at each direction was obtained from the [16]:

$$
R=\frac{\varepsilon_{W}}{\varepsilon_{T}}=\frac{\ln \left(\frac{W_{0}}{W_{\mathrm{f}}}\right)}{\ln \left(\frac{T_{0}}{T_{\mathrm{f}}}\right)}
$$

where $\varepsilon_{W}$ is the lateral strain, $\varepsilon_{T}$ is the thickness strain, $W_{0}$ is the initial width, $W_{\mathrm{f}}$ is the final width, and $T_{0}$ and $T_{\mathrm{f}}$ are the initial and final thicknesses, respectively. Tab. 3 shows all the results.

Table 3 Summary of the anisotropy
\begin{tabular}{|l|c|c|c|c|c|c|}
\hline \multicolumn{2}{|c|}{$0^{\circ}$} & \multicolumn{2}{c|}{$45^{\circ}$} & \multicolumn{2}{c|}{$90^{\circ}$} \\
\cline { 2 - 7 } & $\varepsilon_{W}$ & $\varepsilon_{T}$ & $\varepsilon_{W}$ & $\varepsilon_{T}$ & $\varepsilon_{W}$ & $\varepsilon_{T}$ \\
\hline Sample1 & 12.35 & 0.80 & 12.25 & 0.84 & 12.34 & 0.83 \\
\hline Sample2 & 12.34 & 0.81 & 12.23 & 0.82 & 12.33 & 0.81 \\
\hline Sample 3 & 12.30 & 0.83 & 12.20 & 0.82 & 12.36 & 0.80 \\
\hline Mean & 12.33 & 0.81 & 12.22 & 0.82 & 12.34 & 0.81 \\
\hline Anisotropy coefficient & \multicolumn{7}{|c|}{0.82} & 0.84 & 0.82 \\
\hline $\begin{array}{l}\text { Mean of anisotropy } \\
\text { coefficient }\end{array}$ & \multicolumn{7}{|c|}{0.83} \\
\hline
\end{tabular}

\subsection{CNC Milling Machine}

In this experiment, a 3-axis Gate-Precision CNC milling machine was used to produce the part. The machine, which is shown in Fig. 4, is located at King Saud University, at the industrial engineering lab. The specifications of the $\mathrm{CNC}$ vertical machine are stated in Tab. 4.

Table 4 Machine specifications

\begin{tabular}{|l|c|}
\hline \multicolumn{1}{|c|}{ CNC operating System } & ANILAM \\
\hline Number of Axis & 3 \\
\hline Table Loading Capacity (kg) & 800 \\
\hline Spindle Speed (rpm) & 6000 \\
\hline
\end{tabular}

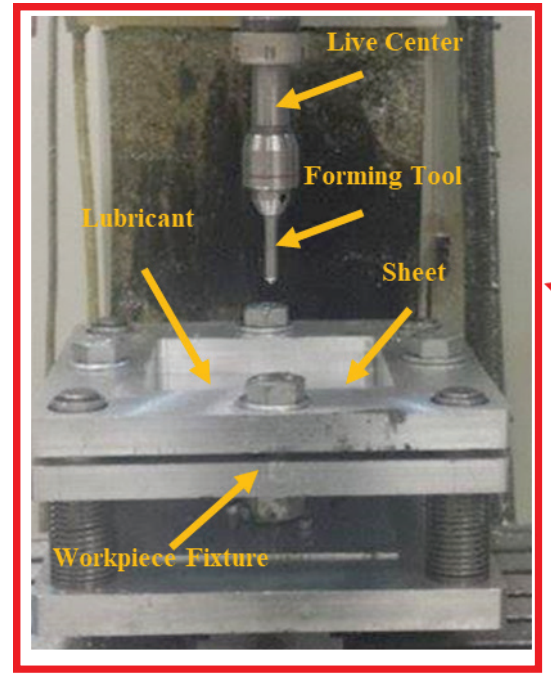

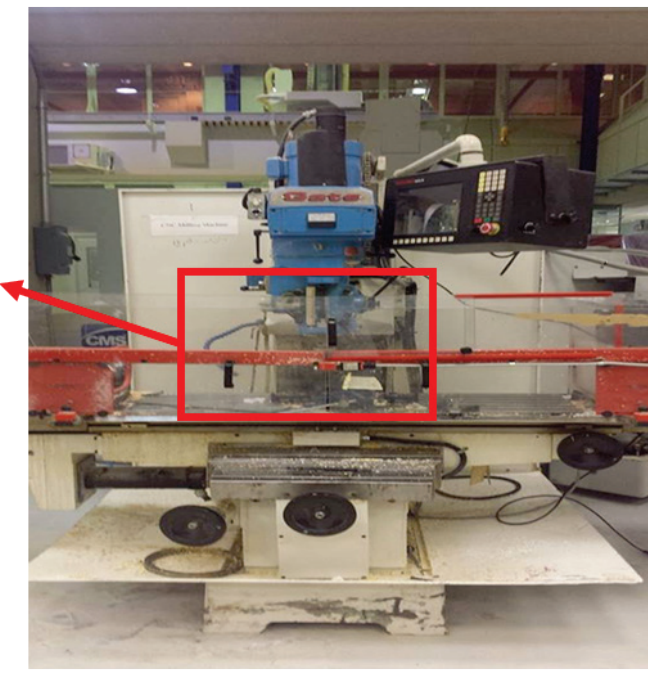

b

Figure 4 Three axis milling machining setup; (a) Zoomed-in view of the workpiece fixture (b) Three axis milling machining setup

\subsection{Depth Measurement}

The part depth was measured using a coordinate measuring machine $(\mathrm{CMM})$ with an accuracy of $2 \mu \mathrm{m}$ and a probe diameter of $3 \mathrm{~mm}$, as shown in Fig. 5. To estimate the dimensional accuracy, the errors in the final part depth were estimated. The part depth was calculated as the distance between the cone top and bottom. The error was calculated as the difference between the actual and designed part depth.

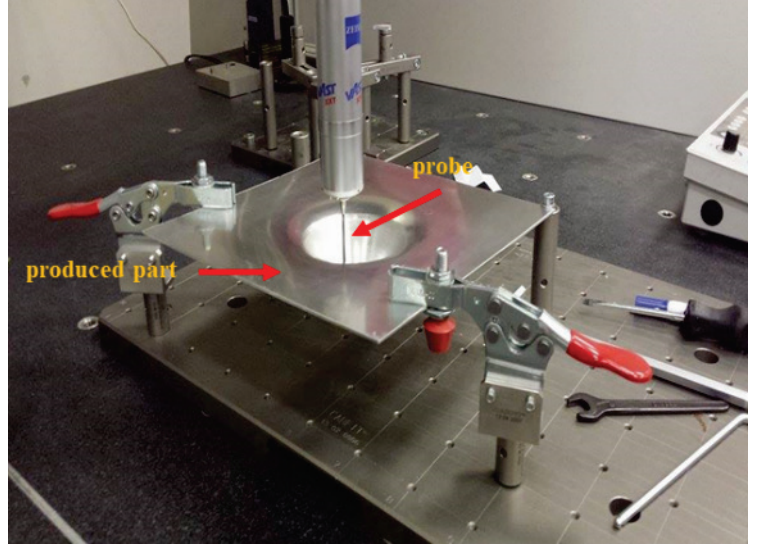

Figure 5 Part depth measurement with CMM 


\subsection{Experimental Conditions}

Regarding the design of the experiment, full factorial was used with four factors; two levels $\left(2^{4}\right)$ and two replications were used to estimate the significance of the process parameter effects and their interactions on the part depth. This process parameters were selected based on pilot runs and the literature $[1 ; 7 ; 10 ; 17]$. The selected process parameters were step size, sheet thickness, tool diameter, and feed rate. Tab. 5 shows the process parameters and their levels.

Table 5 Process parameters and their levels

\begin{tabular}{|l|c|c|}
\hline Input process parameters & Level 1 & Level 2 \\
\hline Tool diameter $(A)$ & $10 \mathrm{~mm}$ & $20 \mathrm{~mm}$ \\
\hline Feed rate $(B)$ & $500 \mathrm{~mm} / \mathrm{min}$ & $1000 \mathrm{~mm} / \mathrm{min}$ \\
\hline Step size $(C)$ & $0.5 \mathrm{~mm}$ & $1 \mathrm{~mm}$ \\
\hline Sheet thickness $(D)$ & $1 \mathrm{~mm}$ & $2 \mathrm{~mm}$ \\
\hline
\end{tabular}

Analysis of Variance (ANOVA) was carried out using Minitab 16. All terms were included in the first analysis. To obtain the best model, the models were filtered by progressively eliminating non-significant terms according to the P-value $[8,11,25]$. The terms with high P-value were eliminated first, then, from the remaining terms in the model, the non-significant were eliminated, and the refining process was repeated until a model whose all its terms were significant was obtained. A model refinement method was carried out to eliminate the readings with large residuals from the final reduced model [8, 22]. As Hoaglin and Welsch [12] recommend, standardized residuals were used to eliminate readings. Moreover, there was no certain boundary for the standardized residuals to remove the readings; therefore, in this experiment two replicates were performed. Thus, only combinations with standardized residuals $>3.0$ or $<-3$ could be removed from the proposed model. Tab. 6 presents the results for the selected response in a random order.

Table 6 Design of experiments and results for part depth

\begin{tabular}{|c|c|c|c|c|c|c|c|c|c|c|c|}
\hline No. & $A$ & $B$ & $C$ & $D$ & Depth $(\mathrm{mm})$ & No. & $A$ & $B$ & $C$ & $D$ & Depth (mm) \\
\hline 1 & 10 & 500 & 1 & 1 & 50.9162 & 25 & 20 & 500 & 1 & 1 & 49.0868 \\
\hline 2 & 20 & 1000 & 0.5 & 2 & 51.4227 & 26 & 20 & 1000 & 1 & 1 & 50.0778 \\
\hline 3 & 20 & 1000 & 0.5 & 1 & 50.7776 & 27 & 20 & 500 & 1 & 2 & 49.6504 \\
\hline 4 & 20 & 500 & 0.5 & 2 & 49.672 & 28 & 10 & 1000 & 0.5 & 2 & 50.6695 \\
\hline 5 & 10 & 500 & 0.5 & 1 & 49.27 & 29 & 10 & 1000 & 1 & 1 & 50.8379 \\
\hline 6 & 10 & 500 & 0.5 & 1 & 51.8542 & 30 & 20 & 500 & 1 & 1 & 47.9894 \\
\hline 7 & 10 & 500 & 1 & 1 & 48.1099 & 31 & 10 & 1000 & 1 & 1 & 51.7173 \\
\hline 8 & 20 & 500 & 0.5 & 1 & 50.9495 & 32 & 10 & 500 & 0.5 & 2 & 48.5773 \\
\hline 9 & 20 & 500 & 0.5 & 2 & 50.9214 & 33 & 10 & 1000 & 0.5 & 2 & 48.5485 \\
\hline 10 & 10 & 1000 & 0.5 & 1 & 50.9143 & 34 & 20 & 1000 & 1 & 2 & 50.6857 \\
\hline 11 & 20 & 1000 & 0.5 & 2 & 49.4499 & 35 & 10 & 1000 & 1 & 2 & 48.1857 \\
\hline 12 & 10 & 1000 & 0.5 & 1 & 51.7445 & 36 & 20 & 1000 & 1 & 2 & 50.5263 \\
\hline 13 & 20 & 500 & 1 & 2 & 51.641 & 37 & 20 & 500 & 1 & 1 & 50.6021 \\
\hline 14 & 20 & 500 & 0.5 & 1 & 51.5143 & 38 & 20 & 1000 & 0.5 & 1 & 50.6921 \\
\hline 15 & 10 & 500 & 1 & 2 & 48.0071 & 39 & 10 & 500 & 1 & 2 & 48.0184 \\
\hline 16 & 20 & 1000 & 1 & 1 & 48.3681 & 40 & 10 & 1000 & 1 & 2 & 47.8036 \\
\hline 17 & 10 & 500 & 0.5 & 2 & 48.437 & 41 & 20 & 500 & 1 & 1 & 51.8326 \\
\hline 18 & 10 & 1000 & 0.5 & 2 & 48.3395 & 42 & 20 & 1000 & 1 & 1 & 51.8178 \\
\hline 19 & 20 & 1000 & 1 & 2 & 48.6197 & 43 & 20 & 500 & 1 & 2 & 51.7973 \\
\hline 20 & 10 & 1000 & 1 & 2 & 48.5375 & 44 & 10 & 1000 & 0.5 & 2 & 48.544 \\
\hline 21 & 20 & 1000 & 1 & 2 & 50.69 & 45 & 10 & 1000 & 1 & 1 & 48.5138 \\
\hline 22 & 20 & 1000 & 0.5 & 1 & 48.9938 & 46 & 20 & 500 & 1 & 1 & 51.7884 \\
\hline 23 & 10 & 500 & 1 & 2 & 52.3792 & 47 & 10 & 1000 & 1 & 1 & 48.2425 \\
\hline 24 & 10 & 1000 & 1 & 2 & 52.2337 & 48 & 10 & 500 & 0.5 & 2 & 48.229 \\
\hline
\end{tabular}

\section{RESULTS}

This section provides the ANOVA results for depth measurement, the effect of the parameters on this value, its interaction plots, and its surface plots. In addition, a brief and particular description of the experimental results and their interpretation are presented.

\subsection{ANOVA Results for Depth}

Tab. 7 presents the final result of ANOVA of part depth after eliminating non-significant terms. Three determination coefficients were used to evaluate the predictive model adequacy, which were $R$-squared, adjusted $R$-squared, and predicted $R$-squared, as given in Tab. 7. From the table, it can be seen that, based on an adjusted R-squared value, a variability of the response data is explained $90.40 \%$ by the model. Moreover, the predicted R-squared value of $88.47 \%$ indicates that the developed predictive model is adequate and can provide good predicted results.

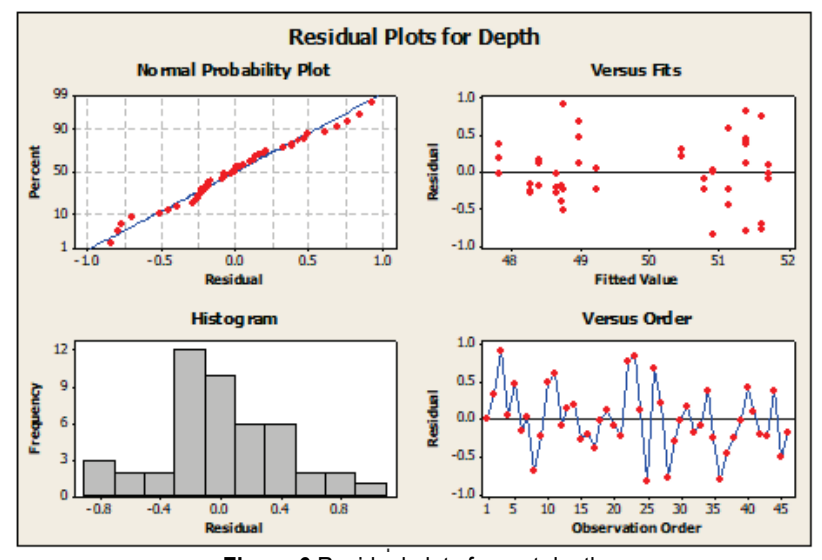

Figure 6 Residual plots for part depth 
Fig. 6 shows residuals plot versus the order of fits and observations. Apparently, the residuals show no pattern and are distributed randomly against both orders of the fitted and observation values. The testing of residuals normality was performed using the Anderson - Darling test. In addition, the results show that the residuals values are normal with the $p$-value of the test $=0.413>0.05$ and display that the residuals lie reasonably near to a straight line, as shown in Fig. 7.

Examining the adjusted sum of squares (Adj SS), Tab. 8 shows the contribution of each significant factor and interaction. Obviously, it can be concluded that factor $A$ (tool diameter) has the largest influence on the part depth. This is followed by factor $D$ (sheet thickness), then by the interaction $A, B$, and $C$. Therefore, it can be said that choosing a machine for the SPIF process is determined mostly by these three factors: $A, B$, and $C$. Meanwhile, feed rate has no significant influence on part depth.

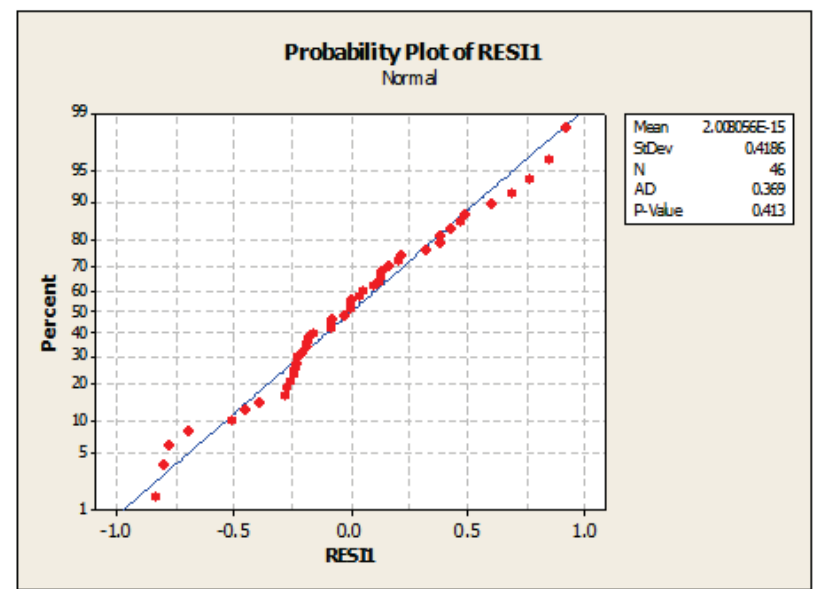

Figure 7 Probability of normal plot for Part depth

Table 7 Results of ANOVA for part depth

\begin{tabular}{|c|c|c|c|c|c|c|}
\hline Source & $D F$ & Seq SS & Adj SS & Adj $M S$ & $F$ & $P$ \\
\hline Main Effects & 4 & 83.7899 & 82.0925 & 20.5231 & 101.51 & 0 \\
\hline$A$ & 1 & 79.8063 & 75.8352 & 75.8352 & 375.1 & 0 \\
\hline$B$ & 1 & 0.0808 & 0.0661 & 0.0661 & 0.33 & 0.571 \\
\hline$C$ & 1 & 0.3491 & 0.3491 & 0.3491 & 1.73 & 0.197 \\
\hline$D$ & 1 & 3.5538 & 3.9863 & 3.9863 & 19.72 & 0 \\
\hline 2-Way Interactions & 1 & 1.326 & 1.4725 & 1.4725 & 7.28 & 0.01 \\
\hline$C * D$ & 1 & 1.326 & 1.4725 & 1.4725 & 7.28 & 0.01 \\
\hline 3-Way Interactions & 1 & 1.7636 & 1.7636 & 1.7636 & 8.72 & 0.005 \\
\hline$A * B * C$ & 1 & 1.7636 & 1.7636 & 1.7636 & 8.72 & 0.005 \\
\hline Residual Error & 39 & 7.8847 & 7.8847 & 0.2022 & & \\
\hline Pure Error & 30 & 5.4486 & 5.4486 & 0.1816 & & \\
\hline Total & 45 & 94.7642 & & & \\
\hline \multicolumn{7}{|l|}{$\mathrm{R}-\mathrm{Sq}=91.68 \% \mathrm{R}-\mathrm{Sq}(\mathrm{pred})=88.47 \% \mathrm{R}-\mathrm{Sq}(\mathrm{adj})=90.40 \%$} \\
\end{tabular}

Table 8 Percentage contribution for part depth

\begin{tabular}{|c|c|}
\hline Item & Contribution $\%$ \\
\hline$A$ & 80 \\
\hline$D$ & 4.2 \\
\hline$C * D$ & 1.5 \\
\hline$A * B * C$ & 1.9 \\
\hline Pure error & 5.8 \\
\hline
\end{tabular}

\subsection{The Effect Parameters on Part Depth}

Fig. 8 shows the relations between part depth and tool diameter $(A)$, and sheet thickness $(D)$. This figure presents the main impact of tool diameter $(A)$, and sheet thickness $(D)$ on the part depth. According to the former analysis, it can be observed that the main impacts are found to be statistically significant on the part depth. It can be seen that when tool diameter $(A)$ increases from 10 to $20 \mathrm{~mm}$, the part depth will be increased, while if factor $D$ increases from 1 to $2 \mathrm{~mm}$, the part depth will be decreased.

Table 9 Multiple response prediction for part depth

\begin{tabular}{|c|c|c|c|c|}
\hline $\begin{array}{c}A \\
(\mathrm{~mm})\end{array}$ & $\begin{array}{c}B \\
(\mathrm{~mm} / \mathrm{min})\end{array}$ & $\begin{array}{c}C \\
(\mathrm{~mm})\end{array}$ & $\begin{array}{c}D \\
(\mathrm{~mm})\end{array}$ & $\begin{array}{c}\text { Part Depth Fit } \\
(\mathrm{mm})\end{array}$ \\
\hline 15 & 752 & 0.747 & 1.304 & 0.4999 \\
\hline
\end{tabular}

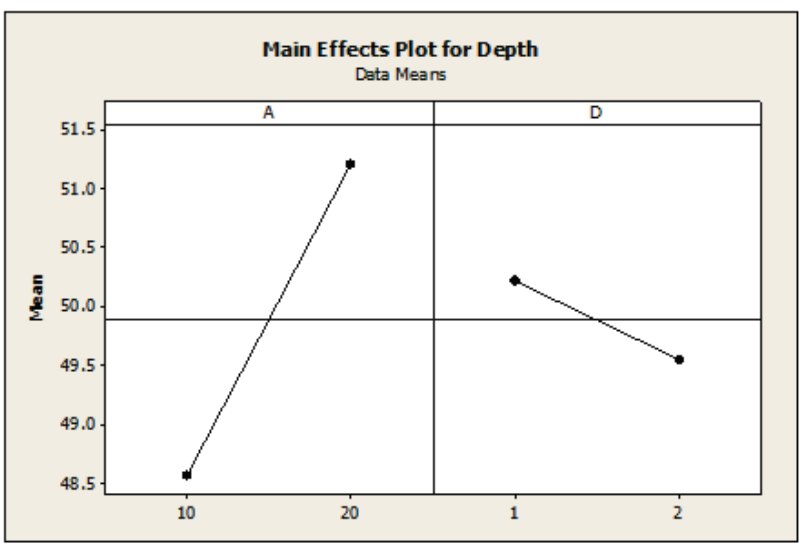

Figure 8 Main effects plot for part depth

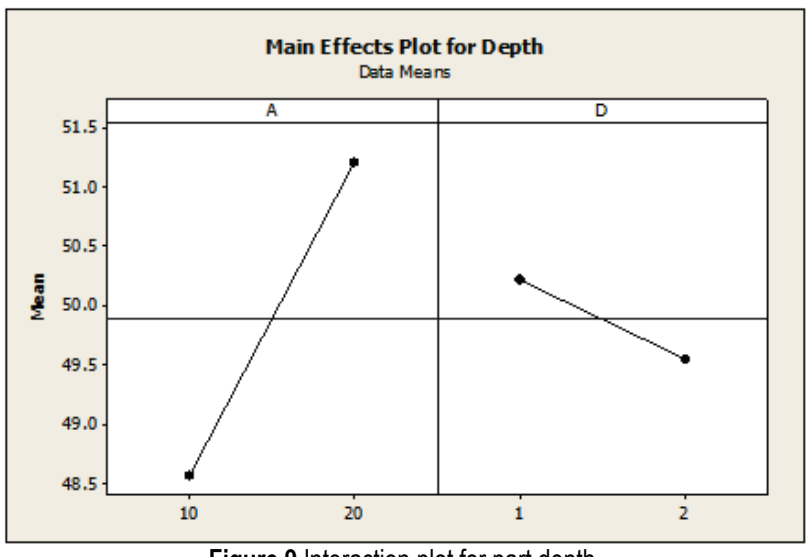

Figure 9 Interaction plot for part depth 


\subsection{Interaction Plot for Part Depth}

Fig. 9 displays the influences of the interaction between the sheet thickness and the step size. According to the former analysis, the influences of the interactions $(C * D)$ are statistically significant to the part depth. The interaction plot shows that a high step size $(C)$ and a high sheet thickness $(D)$ contribute to increase the part depth.

\subsection{Surface Plot for Part Depth}

From the surface graphs, Fig. 10 shows that the target of the part depth is obtained when the step size is low and sheet thickness is high.

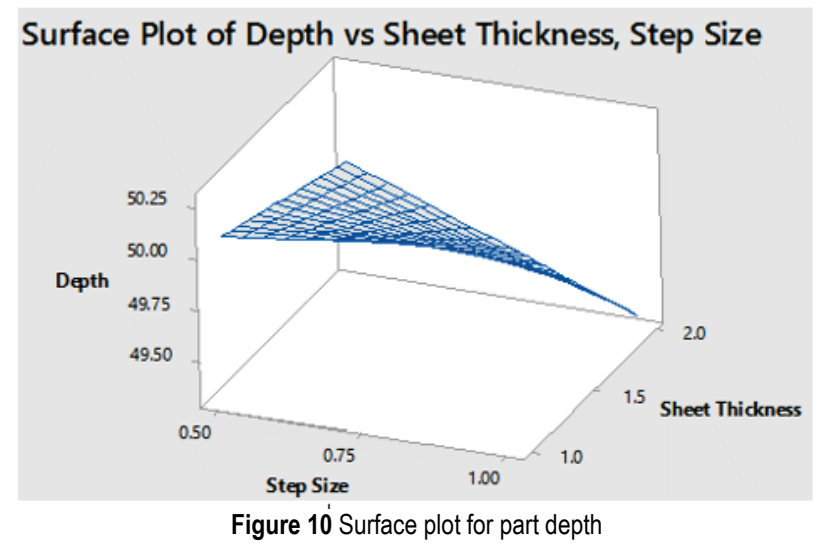

\subsection{Regression and Optimization for Part Depth}

The regression model of the part depth is considered as follows:

Part Depth $=39.96+0.659 * A+0.00770 * B+7.98 * C+$

$0.460 * D-0.000547 * A * B-0.442 * A * C-0.00863 * B * C$

$-1.383 * C * D+0.000607 * A * B * C$

The optimum condition was found to be as given in Tab. 8 and illustrated by Fig. 11. The minimum part depth was targeted to be approximately 50 and resulted in medium tool diameter, medium feed rate, medium step size, and medium sheet thickness.

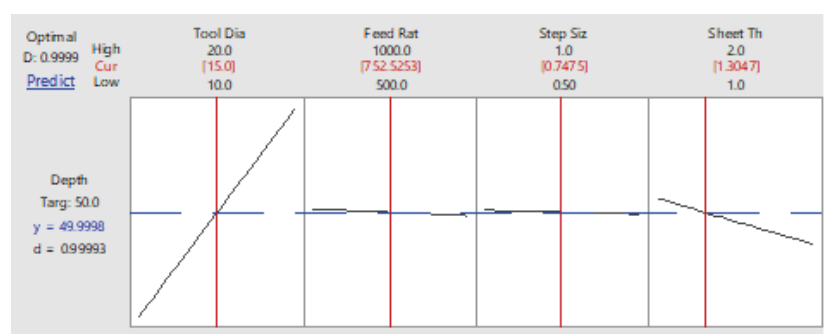

Figure 11 Optimization for part depth

\section{DISCUSSION}

Previous work on the stainless steel AISI 304 has revealed that for higher tool diameters, the part depth in SPIF decreases [7]. In this paper, the part depth increased when the tool diameter decreased, this result is similar to that found by Le et al. [17]. Other researchers have determined the influence of the tool diameter, spindle speed, step size, and sheet thickness on the polyvinylchloride formability [5]. In the present work, high step size and high sheet thickness (D) contributed to increase the part depth. This part depth behavior of polyvinylchloride is similar to that found by [5] in the case of tool diameter and step size. Moreover, it can be found that sheet thickness affects part depth as it appears in sheet metal.

\section{CONCLUSIONS}

In the current research, SPIF has been studied to examine the influences of key parameters on the depth of a formed part through full factorial design of experiments. Four parameters were studied: feed rate, tool diameter, sheet thickness, and step size. A commercially available aluminum alloy AA 1050-H14 was used for producing a truncated cone shape. This shape was selected due to its easiness of forming and measuring. In this study, a fixture was designed to facilitate the forming process on a $\mathrm{CNC}$ milling machine. The following conclusions were found from the present work:

- It was found that tool diameter and sheet thickness are both statistically significant on part depth. It can be observed that when tool diameter ranges from 10 to 20 $\mathrm{mm}$, the part depth increases with the increase of tool diameter. It is evident that the tool diameter has the greatest effect on the part depth.

- The interaction between both sheet thickness and tool diameter is significant for part depth. It can be seen that when the sheet thickness increased from 1 to $2 \mathrm{~mm}$ the part depth decreased.

- The part quality is controlled mainly by the tool diameter and the sheet thickness. A correct combination of these two process parameters would result in a part with fewer flaws.

Future work for this study will investigate the extra factors that affect part depth including sheet material, machine vibrations, and fixture stiffness. In addition, finite element analysis for the SPIF process will be performed to study the effect of more factors, levels and materials, as well as to obtain a deeper insight of the internal deformation mechanism.

\section{Acknowledgments}

The authors would like to acknowledge the support provided by the Deanship of Scientific Research at King Saud University, through the Research Centre at the College of Engineering.

\section{REFERENCES}

[1] Ambrogio, G., Cozza, V., Filice, L., \& Micari, F. (2007). An analytical model for improving precision in single point incremental forming. Journal of Materials Processing Technology, 191(1), 92-95. https://doi.org/10.1016/j.jmatprotec.2007.03.079

[2] Ambrogio, G., De Napoli, L., Filice, L., Gagliardi, F., \& Muzzupappa, M. (2005). Application of Incremental Forming process for high customised medical product manufacturing. Journal of Materials Processing Technology, 162, 156-162. 
https://doi.org/10.1016/j.jmatprotec.2005.02.148

[3] Amino, H., Lu, Y., Ozawa, S., Fukuda, K., \& Maki, T. (2002). Dieless NC forming of automotive service panels. Paper presented at the Proceedings of the conference on Advanced Techniques of Plasticity.

[4] Amino, M., Mizoguchi, M., Terauchi, Y., \& Maki, T. (2014). Current Status of "Dieless" Amino's Incremental Forming. Procedia Engineering, 81, 54-62. https://doi.org/10.1016/j.proeng.2014.09.128

[5] Bagudanch, I., Garcia-Romeu, M., Centeno, G., ElíasZúñiga, A., \& Ciurana, J. (2015). Forming force and temperature effects on single point incremental forming of polyvinylchloride. Journal of Materials Processing Technology, 219, 221-229. https://doi.org/10.1016/j.jmatprotec.2014.12.004

[6] Bambach, M., Hirt, G., \& Junk, S. (2003). Modelling and experimental evaluation of the incremental $\mathrm{CNC}$ sheet metal forming process. Paper presented at the $7^{\text {th }}$ International Conference on Computational Plasticity. https://doi.org/10.1063/1.1766822

[7] Centeno, G., Bagudanch, I., Martínez-Donaire, A., GarciaRomeu, M. L., \& Vallellano, C. (2014). Critical analysis of necking and fracture limit strains and forming forces in single-point incremental forming. Materials \& Design, 63, 20-29. https://doi.org/10.1016/j.matdes.2014.05.066

[8] Ding, T., Zhang, S., Wang, Y., \& Zhu, X. (2010). Empirical models and optimal cutting parameters for cutting forces and surface roughness in hard milling of AISI H13 steel. The International Journal of Advanced Manufacturing Technology, 51(1-4), 45-55. https://doi.org/10.1007/s00170-010-2598-2

[9] Do, V.-C. \& Kim, Y.-S. (2017). Effect of Hole Lancing on the Forming Characteristic of Single Point Incremental Forming. Procedia Engineering, 184, 35-42. https://doi.org/10.1016/j.proeng.2017.04.068

[10] Filice, L., Ambrogio, G., \& Micari, F. (2006). On-line control of single point incremental forming operations through punch force monitoring. CIRP AnnalsManufacturing Technology, 55(1), 245-248. https://doi.org/10.1016/S0007-8506(07)60408-9

[11] Fydrych, D. \& Rogalski, G. (2011). Effect of shieldedelectrode wet welding conditions on diffusion hydrogen content in deposited metal. Welding International, 25(03), 166-171. https://doi.org/10.1016/S0007-8506(07)60408-9

[12] Hoaglin, D. C. \& Welsch, R. E. (1978). The hat matrix in regression and ANOVA. The American Statistician, 32(1), 17-22.https://doi.10.1080/09507116.2010.540828

[13] Hussain, G. \& Gao, L. (2007). A novel method to test the thinning limits of sheet metals in negative incremental forming. International Journal of Machine Tools and Manufacture, 47(3), 419-435. https://doi.org/10.1016/j.jimachtools.2006.06.015

[14] Jeswiet, J. (2000). Rapid proto-typing with incremental single point forming. Revue internationale de CFAO et d'informatique graphique, 15(2-4), 177-183. https://doi.org/10.1016/j.jimachtools.2006.06.015

[15] Jeswiet, J., Micari, F., Hirt, G., Bramley, A., Duflou, J., \& Allwood, J. (2005). Asymmetric single point incremental forming of sheet metal. CIRP Annals-Manufacturing Technology, 54(2), 88-114. https://doi.org/10.1016/S0007-8506(07)60021-3

[16] Kalpakjian, S., Schmid, S. R., \& Kok, C.-W. (2008). Manufacturing processes for engineering materials. Pearson-Prentice Hall.

[17] Le, V., Ghiotti, A., \& Lucchetta, G. (2008). Preliminary studies on single point incremental forming for thermoplastic materials. International journal of material forming, 1(1), 1179-1182. https://doi.org/10.1007/s12289-008-0191-0

[18] Lievers, W., Pilkey, A., \& Lloyd, D. (2004). Using incremental forming to calibrate a void nucleation model for automotive aluminum sheet alloys. Acta Materialia, 52(10), 3001-3007. https://doi.org/10.1016/j.actamat.2004.03.002

[19] Maki, T. (2005). Sheet Fluid Forming and Sheet Dieless NC Forming. Amino Corporation, Japan

[20] Matsubara, S. (1994). Incremental Backward Bulge Forming of a Sheet Metal with a Hemispherical Head Tool-A Study of a Numerical Control Forming System II. Journal-Japan Society for Technology of Plasticity, 35, 1311-1311.

[21] Oleksik, V., Pascu, A., Deac, C., Fleaca, R., Roman, M., \& Bologa, O. (2010). The influence of geometrical parameters on the incremental forming process for knee implants analyzed by numerical simulation. NUMIFORM 2010, 12081215. https://doi.org/10.1063/1.3457520

[22] Patel, T. C., Patel, L. S., \& Patel, B. C. (2015). Analysis and prediction of milling process on Vertical Milling Centre (VMC) by using Response Surface Methodology (RSM). International Journal for Innovative Research in Science and Technology, 1(7), 205-212

[23] Silva, M., Alves, L., \& Martins, P. (2010). Single point incremental forming of PVC: Experimental findings and theoretical interpretation. European journal of mechanicsA/Solids, 29(4), 557-566. https://doi.org/10.1016/j.euromechsol.2010.03.008

[24] Silva, M. B., Nielsen, P. S., Bay, N., \& Martins, P. A. (2011). Failure mechanisms in single-point incremental forming of metals. The International Journal of Advanced Manufacturing Technology, 56(9-12), 893-903. https://doi.org/10.1007/s00170-011-3254-1

[25] Zhang, Y. \& Chou, K. (2008). A parametric study of part distortions in fused deposition modelling using threedimensional finite element analysis. Proceedings of the Institution of Mechanical Engineers, Part B: Journal of Engineering Manufacture, 222(8), 959-968. https://doi.org/10.1243/09544054JEM990

\section{Contact information:}

\section{Adel AL-SHAYEA}

College of Engineering, Industrial Engineering Department,

King Saud University,

P. O. Box 800, 11421 Riyadh,

Kingdom of Saudi Arabia

\section{Abdulmajeed DABWAN}

Corresponding author

College of Engineering, Industrial Engineering Department,

King Saud University,

P. O. Box 800, 11421 Riyadh,

Kingdom of Saudi Arabia

abmj999@yahoo.com

\section{Adham E RAGAB}

College of Engineering, Industrial Engineering Department, King Saud University,

P. O. Box 800,11421 Riyadh,

Kingdom of Saudi Arabia

\section{Mustafa M. NASR}

College of Engineering, Industrial Engineering Department,

King Saud University,

P. O. Box 800, 11421 Riyadh,

Kingdom of Saudi Arabia

eng.alhyal@gmail.com

\section{Husam KAID}

College of Engineering, Industrial Engineering Department,

King Saud University,

P. O. Box 800,11421 Riyadh,

Kingdom of Saudi Arabia 